\title{
Eustachian Tube Dysfunction and Wideband Absorbance Measurements at Tympanometric Peak Pressure and $0 \mathrm{daPa}$
}

DOI: $10.3766 /$ jaaa.18002

\author{
Sreedevi Aithal ${ }^{* \dagger}$ \\ Venkatesh Aithal*† \\ Joseph Kei $\dagger$ \\ Shane Anderson \\ Simon Liebenberg
}

\begin{abstract}
Background: Although wideband absorbance (WBA) provides important information about middle ear function, there is limited research on the use of WBA to evaluate eustachian tube dysfunction (ETD). To date, WBA obtained under pressurized condition has not been used to evaluate ETD.

Purpose: The objective of the study was to compare WBA at $0 \mathrm{daPa}$ and tympanometric peak pressure (TPP) conditions in healthy ears and ears with ETD.

Research Design A cross-sectional study design was used.

Study Sample A total of 102 healthy ears from 79 participants (mean age $=10.0 \mathrm{yr}$ ) and 43 ears from 32 patients with ETD (mean age $=16.0 \mathrm{yr}$ ) were included in this cross-sectional study. WBA was measured at $0 \mathrm{daPa}\left(\mathrm{WBA}_{0}\right)$ and TPP WBA at TPP $\left(\mathrm{WBA}_{\mathrm{TPP}}\right)$.
\end{abstract}

Data Collection and Analysis: WBA results were analyzed using descriptive statistics and $t$-tests with the Bonferroni correction. An analysis of variance with repeated measures was applied to the data.

Results: $W_{B A}$ was significantly lower in the ETD group than in the control group. The WBA of the control group demonstrated a broad peak between 1.25 and $4 \mathrm{kHz}$, whereas the WBA $\mathrm{W}_{0}$ of the ETD group

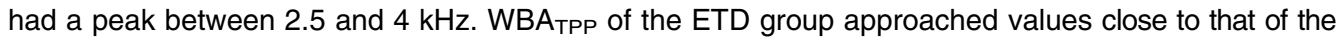
control group. In the control group, WBA $\mathrm{WPP}_{\text {TP }}$ was only 0.06 to 0.09 higher than $\mathrm{WBA}_{0}$, whereas in the ETD group, $\mathrm{WBA}_{\text {TPP }}$ was 0.29 to 0.42 higher than $\mathrm{WBA}_{0}$ between 0.6 and $1.5 \mathrm{kHz}$. A differential pattern of WBA at TPP relative to 0 daPa was observed between ears with ETD and ears with otitis media with effusion (OME) and negative middle ear pressure (NMEP).

Conclusions: Hence, a comparison of $\mathrm{WBA}_{0}$ and $\mathrm{WBA}_{\mathrm{TPP}}$ can provide potentially useful diagnostic information, and hence can be used as an adjunct tool to evaluate ETD. This is important especially in young children or some adults who are unable to perform maneuvers such as Toynbee or Valsalva during ETD assessment. Further research is needed to verify the results using test performance measures to determine whether $\mathrm{WBA}_{0}$ and $\mathrm{WBA}_{\mathrm{TPP}}$ can objectively determine the presence of ETD or OME with NMEP.

Key Words: eustachian tube dysfunction, wideband absorbance

Abbreviations: ANOVA = analysis of variance; daPa = deca pascals; $\mathrm{ENT}=$ ear, nose and throat; $\mathrm{ET}=$
eustachian tube; ETD = eustachian tube dysfunction; $\mathrm{MEP}=$ middle ear pressure; $\mathrm{nHL}=$ normal hearing
level; NMETP = negative middle ear pressure; $\mathrm{SD}=$ standard deviation; TEOAE = transient evoked
optoacoustic emissions; TPP = tympanometric peak pressure; WBA = wideband absorbance; $\mathrm{WBA}_{0}=$
WBA at 0 daPa; $\mathrm{WBA}_{\mathrm{TPP}}=\mathrm{WBA}$ at TPP; WBT = wideband tympanometry

*Department of Audiology, The Townsville Hospital, Townsville, Australia; †Research Unit for Children, School of Health, and Rehabilitation Sciences, University of Queensland, Faculty of Healthy Sciences, St. Lucia, Australia; $\ddagger$ Department of ENT, The Townsville Hospital, Townsville, Australia

Corresponding author: Sreedevi Aithal, Department of Audiology, The Townsville Hospital, Townsville 4810, Australia; Email: Sreedevi.aithal@ health.qld.gov.au

This study was supported by the Queensland Health New Technology Funding and Evaluation Program grant (HQ000249 NTFEP2014/15).

This paper was presented at the biennial National Conference of Audiology Australia conference (Sydney, May 21-23, 2018). 


\section{INTRODUCTION}

$\mathrm{E}$ ustachian tube dysfunction (ETD) is one of the most common problems seen in ear nose and throat (ENT) clinics with an estimated prevalence of about $1 \%$ in adults (Tysome, 2015). With ETD, the pressure behind the tympanic membrane cannot be equalized to ambient atmospheric pressure, which results in negative middle ear pressure (NMEP) (Bluestone and Klein, 2007). Lildholdt (1980) studied a group of unselected 352 children during a 12-month period and reported that 25-50\% of the children had NMEP. The eustachian tube (ET) plays a pivotal role in the pathogenesis of otitis media with effusion (OME) and cholesteatoma and has a major impact on the outcome of middle ear surgery (Podoshin et al, 1996; Schröder et al, 2015). Hence, it is important to accurately determine the status of the prior ET function.

There are several tests to assess the ET function. Tympanometry is a reliable method to determine the middle ear pressure (MEP) when the tympanic membrane is intact. The ear canal pressure at which the peak of the tympanogram occurs is the tympanometric peak pressure (TPP). A resting pressure that is highly negative is associated with some degree of ET obstruction. However, TPP is an indicator, but not a direct measure of the pressure in the middle ear space (Hunter and Shahnaz, 2014). Elner et al (1971) demonstrated that the mobility of tympanic membrane increases in cases with a slightly reduced ET function as compared with cases with normal ET function. In an experimental study on human temporal bones, Renall and Holmquist (1976) demonstrated that there is a discrepancy between the tympanometrically (indirectly) recorded MEP and the MEP as measured manometrically, directly from the middle ear.

A single measurement of normal resting MEP is not always indicative of normal ET function, as it does not provide indication of the pressure regulation function of the ET under various conditions of induced MEP. Hence, tests such as Toynbee and Valsalva were developed to provide serial determinations of MEP and indicate the dynamics of the tubal function. However, one obvious problem with these tests is that it is impossible to control the relative amounts of overpressure or underpressure generated in each individual (Bluestone, 2005). In addition, there are other tests such as nine-step inflationdeflation test and questionnaires for diagnosis and followup such as Eustachian tube dysfunction questionnaire 7. However, these are not suitable for routine application with young children where ETD is very common. Furthermore, current tympanometric method of clinical assessment in ears with NMEP cannot rule out the presence of OME (Shaver, 2010).

Wideband absorbance (WBA) is becoming a popular diagnostic tool to assess middle ear function over a wide range of frequencies (Allen et al, 2005; Vander Werff et al, 2007; Hunter et al, 2008; Shahnaz, 2008; Prieve et al, 2013). In recent years, several studies have shown WBA to be effective in identifying middle ear dysfunction and conductive disorders in infants (Sanford et al, 2009; Hunter et al, 2010; Aithal et al, 2014), children (Keefe and Simmons, 2003; Beers et al, 2010; Ellison et al, 2012; Keefe et al, 2012; Prieve et al, 2013), and adults (Margolis et al, 1999; Shahnaz and Bork, 2006; Shahnaz et al, 2009; Nakajima et al, 2012).

Thus far, there are only a few studies that have investigated WBA at ambient pressure in ears with ETD. These studies vary greatly in terms of methodology and clinical samples. For instance, Ibraheem (2014) reported WBA in three adult patients with ETD and reported a significant difference between ETD and control groups at $0.25 \mathrm{kHz}$ only. Beers et al (2010) reported a decrease in absorbance from 0.25 to $6.3 \mathrm{kHz}$ in 54 ears with static NMEP in 5- to 7-year-old children. In a simulated NMEP condition in eight normal ears, Robinson et al (2016) reported the largest and most significant reduction in absorbance from 0.8 to $1.9 \mathrm{kHz}$. Voss et al (2012) studied WBA in cadaveric ears and demonstrated that WBA at frequencies less than $2 \mathrm{kHz}$ decreased with corresponding decrease in NMEP. However, NMEP resulted in increased WBA at frequencies $>3 \mathrm{kHz}$.

WBA can also be measured under pressurized conditions (wideband tympanometry [WBT]). The orderly behavior of WBT and their apparent sensitivity to middle ear disorders might be useful for middle ear assessment (Margolis et al, 1999; Sanford et al, 2013). WBT is reported to be either equal or better than WBA at ambient pressure in identifying middle ear status (Margolis et al, 1999; Keefe and Simmons, 2003; Sanford et al, 2009). Because admittance is highest when the pressures on both sides of the tympanic membrane are equal, it can be hypothesized, that in ears with ETD, the absorbance too will improve when the ear canal is equal to the MEP as compared with ambient pressure.

One method to circumvent the effect of NMEP is to apply a compensatory pressure in the ear canal or measure at TPP. Margolis et al (1999) presented a case study of a 10-year-old boy with a history of recurrent otitis media, conductive hearing loss, and NMEP. They found that although the WBA was reduced at ambient MEP, normal WBA pattern was observed at TPP. Margolis et al suggested that it would be advantageous to assess the middle ear at ambient and TPP in ears with NMEP.

Shaver and Sun (2013) examined WBA in the same ears under normal and experimentally induced NMEP conditions. For the NMEP condition, they reported a decrease in absorbance for low-to-mid frequencies with the largest change occurring between 1 and $1.5 \mathrm{kHz}$. Measurements at compensated NMEP (i.e., positive 
ear canal pressure equal to the negative shift in MEP self-induced by a participant) shifted the WBA to near baseline values. Shaver and Sun, therefore, suggested that the compensation procedure adequately mitigates the effects of NMEP on WBA.

WBA results at any single ear canal pressure do not completely characterize the effects of middle ear pathology, including ETD. Comparison of WBA measurements under pressurized conditions could provide additional clinical information about the dynamics of the ET function that is not available by testing at a single ear canal pressure alone. Despite the demonstration of improvement in WBA under pressurized conditions in laboratory situations, to date, there are no clinical studies that have systematically evaluated pressurized WBA in ears with ETD. The objective of the present study was to compare WBA at TPP ( $\left.\mathrm{WBA}_{\mathrm{TPP}}\right)$ and $0 \mathrm{daPa}$ $\left(\mathrm{WBA}_{0}\right)$ in healthy ears and ears with ETD.

\section{METHOD}

\section{Subjects}

The study was approved by the Townsville Hospital and Health Service Ethics Board. Information brochure about the study was provided to the adults and parents or legal guardians of children and their written consent was obtained. An information brochure was also provided to older children who could read and understand the information.

\section{Control Group}

The control group consisted of children who presented to the ENT and Audiology clinics at the Townsville Hospital with no history of ear or hearing difficulties. Details of participants in the control group are provided in Table 1. This group included 102 healthy ears from 79 participants ( 54 males and 25 females). Inclusion criteria for the control group were (a) normal otoscopy findings and aerated middle ear as judged by an ENT surgeon, (b) negative history of middle ear infection at the time of testing, (c) Jerger's A type tympanograms with MEP between +50 and -100 daPa and static admittance between 0.3 and $1.6 \mathrm{mmho}$, (d) air conduction thresholds less than $20 \mathrm{~dB}$ HL between 0.25 and $8 \mathrm{kHz}$, (e) air bone gap of $<15 \mathrm{~dB}$ at frequencies between 0.25 and $4 \mathrm{kHz}$, and (f) a pass in transient evoked otoacoustic emissions (TEOAEs) as determined by a signal-to-noise ratio of at least $3 \mathrm{~dB}$ at 2,3 , and $4 \mathrm{kHz}$.

\section{ETD Group}

The ETD group consisted of patients diagnosed with ETD without effusion. This group consisted of 43 ears from 32 patients (23 males and 9 females) with a
Table 1. Subject Details

\begin{tabular}{lcc}
\hline & Normal & Eustachian Tube Dysfunction \\
\hline No. of subjects & 79 & 32 \\
Males & 54 & 23 \\
Females & 25 & 9 \\
No. of ears & 102 & 43 \\
$\quad$ Right & 55 & 18 \\
$\quad$ Left & 47 & 25 \\
Age (in years) & & \\
$\quad$ Mean & 10.0 & 16.0 \\
SD & 4.9 & 14.8 \\
Range & $3.7-3.0$ & $3.1-48.1$ \\
\hline
\end{tabular}

diagnosis of ETD and NMEP in at least one ear (Table 1). Diagnosis of ETD was made based on clinical presentation and otomicroscopy by the ENT surgeon. NMEP was determined by $226-\mathrm{Hz}$ tympanometry and participant data were only included in the ETD group if the TPP was $<-100$ daPa. WBA assessment and audiometry were performed following tympanometry.

\section{Procedure}

Tympanometry, otoacoustic emission testing, puretone audiometry, and WBA assessment were performed by a clinical audiologist. Tympanometry was performed using the Interacoustics Titan version 3.1 (IMP440; Interacoustics, Assens, Denmark). A 226-Hz probe tone was swept from +200 to $-400 \mathrm{daPa}$ using a positive to negative sweep direction. Peak MEP and static admittance were recorded.

TEOAE screening test was performed to verify normal cochlear function up to and including the outer hair cells and as an indirect screening of the middle ear status. TEOAEs were performed in a quiet room using the Interacoustics Titan version 3.1 (IMP440). Clicks were presented at $80 \mathrm{~dB}$ SPL under ambient pressure condition. Absolute value and signal-to-noise ratio of the emissions were recorded.

Pure-tone audiometry was conducted using a AC-40 clinical audiometer (Interacoustics, Middelfart, Denmark) at the Townsville Hospital. Measurements were made with TDH-39 earphones (Telephonics, Farmingdale, NY). All testing was carried out in a sound-treated booth with ambient noise less than $30 \mathrm{dBA}$. Hearing thresholds were determined for octave frequencies between 0.25 and $8 \mathrm{kHz}$ using the Hughson-Westlake method.

\section{Wideband Absorbance Measurements and Analysis}

WBA was measured using the Titan (IMP440/ WBT440) module. The probe was fitted with an appropriately sized rubber probe tip and placed in the ear canal. Testing started only when the probe light turned 
green, indicating an adequate probe seal. Click stimuli were presented at $100 \mathrm{~dB}$ SPL ( $65 \mathrm{~dB} \mathrm{nHL})$ with a rate of $21.5 \mathrm{~Hz}$ (Interacoustics, 2015), whereas ear canal pressure was swept from +200 to $-300 \mathrm{daPa}$ at a rate of $200 \mathrm{daPa} / \mathrm{sec}$. A three-dimensional plot of WBA was automatically generated as a function of ear canal pressure and frequency from 0.25 to $8 \mathrm{kHz}$. The Titan device also automatically generated two WBA plots, namely, $\mathrm{WBA}_{0}$ and $\mathrm{WBA}_{\text {TPP. The TPP was determined from a }}$ wideband averaged Tympanogram which shows that WBA against ear canal pressure averaged across a frequency range from 0.8 to $2 \mathrm{kHz}$.

$\mathrm{WBA}_{0}$ and $\mathrm{WBA}_{\mathrm{TPP}}$ were recorded at $1 / 24^{\text {th }}$ octave between 0.23 and $8 \mathrm{kHz}$. Data extraction from the Titan device was performed using MATLAB. For this study, both $\mathrm{WBA}_{0}$ and $\mathrm{WB}_{\text {TPP }}$ were averaged to 16 frequency bands centered at one-third octave frequencies from 0.25 to $8 \mathrm{kHz}$.

\section{Statistical Analysis}

Statistical analysis was performed using the IBM SPSS software version 23 (IBM Corporation, Armonk, NY). A mixed model analysis of variance (ANOVA) was used to analyze data for ears with and without NMEP. The Greenhouse and Geisser (1959) G-G approach was used to compensate for the violation of compound symmetry and sphericity. Data were analyzed using ear status (normal versus ETD) and WBA condition $\left(\mathrm{WBA}_{0}\right.$ versus $\mathrm{WBA}_{\text {TPP }}$ ) as between group factor and frequencies as within group factor. Post hoc analyses were performed using multiple pair-wise comparison tests with Bonferroni adjustments to determine the frequencies at which significant differences existed between control and experimental groups. A $p$ value of $<0.05$ was considered statistically significant for all analyses.

\section{RESULTS}

$T$ he tympanogram classification was based on the system illustrated by Jerger (1970). All 102 ears in the control group had A type tympanograms with a mean TPP of $-21.09 \mathrm{daPa}$ (standard deviation $[\mathrm{SD}]=35.27$, range $=-100$ to $50 \mathrm{daPa}$ ) and mean static admittance of $0.72 \mathrm{mmho}$ ( $\mathrm{SD}=0.34 \mathrm{mmho}$; range $=0.25-2.13 \mathrm{mmho}$ ). In the ETD group, all 43 ears had $C$ type tympanograms with a mean TPP of $-265.81 \mathrm{daPa}(\mathrm{SD}=73.61$; range $=$ -121 to $-441 \mathrm{daPa}$ ) and mean static admittance of 0.91 mmho ( $\mathrm{SD}=0.40 \mathrm{mmho}$; range $=0.22-1.88 \mathrm{mmho}$ ).

TPP was also measured in the control and ETD groups under pressurized condition. Mean TPP obtained in the pressurized condition was similar to that obtained with the $226-\mathrm{Hz}$ tympanogram. In the pressurized condition, mean TPP in control group was $-18.21 \mathrm{daPa}(\mathrm{SD}=32.70$ $\mathrm{daPa}$; range $=-113$ to $49 \mathrm{daPa}$ ) and the mean TPP in the ETD group was $-244.40 \mathrm{daPa}(\mathrm{SD}=84.05 \mathrm{daPa}$; range $=-40$ to $-399 \mathrm{daPa}$ ).

All ears in the control group had normal hearing with air conduction thresholds less than $20 \mathrm{~dB}$ HL at each of the octave frequencies from 0.25 to $8 \mathrm{kHz}$. Bone conduction thresholds were within $10 \mathrm{~dB}$ HL from 0.25 to $4 \mathrm{kHz}$ and the air-bone gap was within $10 \mathrm{~dB}$ at each frequency. The ETD group demonstrated slight to mild conductive hearing loss with mean air conduction thresholds between 20 and $25 \mathrm{~dB}$ HL at $0.25-8 \mathrm{kHz}$ and mean bone conduction thresholds between 5 and $10 \mathrm{~dB} \mathrm{HL}$ at $0.25-4 \mathrm{kHz}$.

Figure 1 illustrates the mean $\mathrm{WBA}_{0}$ and $\mathrm{WBA}_{\mathrm{TPP}}$ from 0.25 to $8 \mathrm{kHz}$ for both control and ETD groups. In both groups, $\mathrm{WBA}_{0}$ was reduced in the low frequencies and gradually increased with frequency until a peak was reached and reduced $>4 \mathrm{kHz}$. The control group demonstrated a broad peaked pattern between

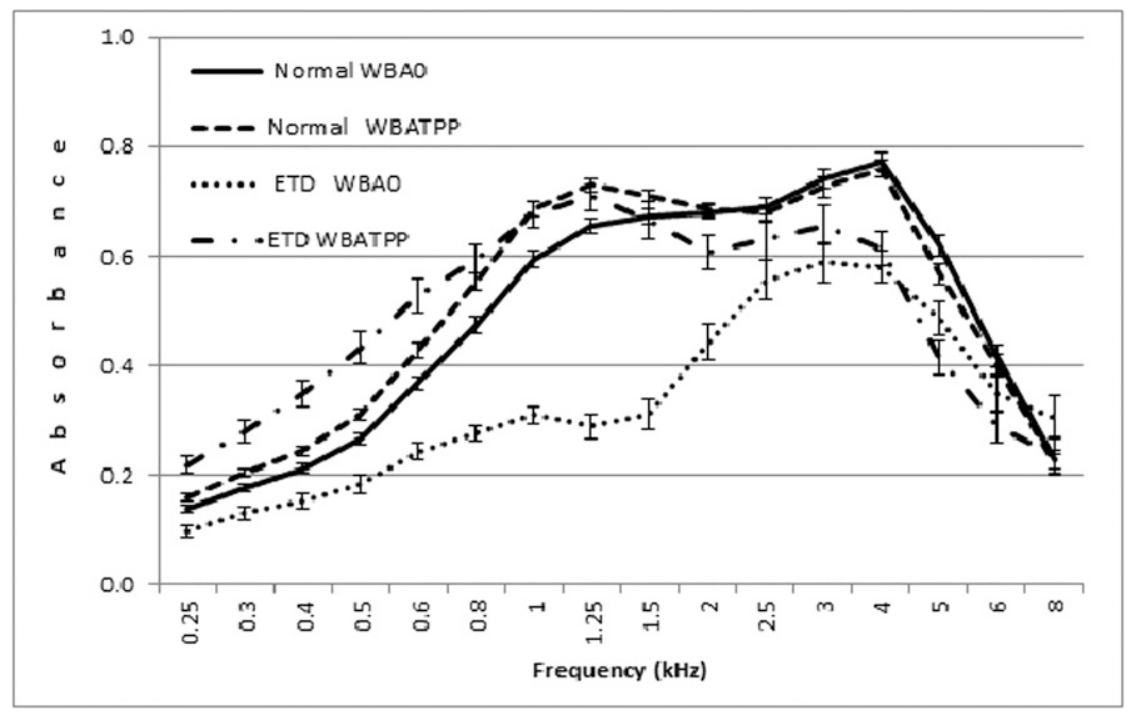

Figure 1. $\mathrm{WBA}_{0}$ and $\mathrm{WBA}_{\mathrm{TPP}}$ in the control and ETD groups. 
1.25 and $4 \mathrm{kHz}$ with $\mathrm{WBA}_{0}$ achieving the highest value of 0.77 at $4 \mathrm{kHz}$. There was a $50 \%$ increase in $\mathrm{WBA}_{0}$ from 0.25 to $1.25 \mathrm{kHz}$. In comparison, $\mathrm{WBA}_{0}$ of the ETD group demonstrated a peak in the high frequencies between 2.5 and $4 \mathrm{kHz}$, with the $\mathrm{WBA}_{0}$ achieving the highest value of 0.61 at $4 \mathrm{kHz}$. The ETD group demonstrated only $20 \%$ increase in $\mathrm{WBA}_{0}$ between 0.25 and $1.5 \mathrm{kHz}$. $\mathrm{WBA}_{0}$ increased steeply $>1.5 \mathrm{kHz}$, reaching a maximum value of 0.61 at $4 \mathrm{kHz}$ and reduced $>4 \mathrm{kHz}$. The mean $\mathrm{WBA}_{0}$ of the ETD group was lower than the mean $\mathrm{WBA}_{0}$ of the control group at all frequencies, except $8 \mathrm{kHz}$.

The $\mathrm{WBA}_{0}$ results were analyzed using an ANOVA with repeated measures, with WBA as the dependent variable and ear status as the independent variable. ANOVA results showed a significant difference in $\mathrm{WBA}_{0}$ between the control and ETD groups $\left[F_{(1,144)}=132.46, p=0.00\right]$. The mean $\mathrm{WBA}_{0}$ of the ETD group was significantly lower than that of the control group at all frequencies between 0.25 and $8 \mathrm{kHz}$ except at $6 \mathrm{kHz}$ (Table 2). Partial eta square was the highest between 0.8 and $2 \mathrm{kHz}(0.32$ $0.58)$ and reduced $<0.8$ and $>2 \mathrm{kHz}(0.08-0.22)$.

As seen in Figure 1, the overall pattern of $\mathrm{WBA}_{\text {TPP }}$ was similar for both groups in that the $\mathrm{WBA}_{\mathrm{TPP}}$ was high between 1 and $4 \mathrm{kHz}$ and reduced $<1 \mathrm{kHz}$ and $>4 \mathrm{kHz}$. $\mathrm{WBA}_{\text {TPP }}$ for the control group showed two large peaks, with the first peak occurring at $1.25 \mathrm{kHz}$ and the second peak at $4 \mathrm{kHz}$. The $\mathrm{WBA}_{\text {TPP }}$ of the ETD group also demonstrated two large peaks occurring at $1.25 \mathrm{kHz}$ and $3 \mathrm{kHz}$, respectively. Mean $\mathrm{WBA}_{\mathrm{TPP}}$ of the ETD group was higher than that of the control group between 0.25 and $0.8 \mathrm{kHz}$ and lower than that of the control group between 1.5 and $6 \mathrm{kHz}$.
An ANOVA with repeated measures with $\mathrm{WBA}_{\text {TPP }}$ as the dependent variable and ear status as independent variable showed no significant main effect for ear status (normal versus ETD) $\left[F_{(1,144)}=0.49, p>0.05\right]$. However, the interaction between frequency and middle ear condition was significant $\left[F_{(4,596)}=11.40, p=\right.$ $0.00]$. The mean $\mathrm{WBA}_{\text {TPP }}$ was significantly different between the two groups at frequencies from 0.25 to 0.6 $\mathrm{kHz}$ and from 4 to $6 \mathrm{kHz}$ (Table 3) with the partial eta square values ranging between 0.06 and 0.1 .

Table 4 shows the difference between $\mathrm{WBA}_{\text {TPP }}$ and $\mathrm{WBA}_{0}\left(\mathrm{WBA}_{\mathrm{TPP}}-\mathrm{WBA}_{0}\right)$ for both control and ETD groups. As seen from the table, the difference between $\mathrm{WBA}_{\text {TPP }}$ and $\mathrm{WBA}_{0}$ was small at all frequencies for the control group compared with the ETD group. There was only 0.02 to 0.09 increase in $\mathrm{WBA}_{\text {TPP }}$ between 0.25 and $1.5 \mathrm{kHz}$ relative to the $\mathrm{WBA}_{0}$ condition in the control group. In comparison, for the ETD group, the $\mathrm{WBA}_{\text {TPP }}$ increased from 0.25 until it reached a peak value of 0.42 at $1.25 \mathrm{kHz}$ and reduced greater than $1.25 \mathrm{kHz}$. The ETD group demonstrated a 0.12 to 0.42 increase in absorbance between 0.25 and $1.25 \mathrm{kHz}$.

An ANOVA with repeated measures was performed with $\mathrm{WBA}_{\mathrm{TPP}}-\mathrm{WBA}_{0}$ as the dependent variable and ear status as the independent variable. The main effect of $\mathrm{WBA}_{\mathrm{TPP}}-\mathrm{WBA}_{0}$ was significantly different for both control $\left[F_{(1,204)}=5.26, p=0.02\right]$ and ETD $\left[F_{(1,84)}=70.86, p=0.00\right]$ groups. Results of the ANOVA analysis (Table 4) demonstrated that for the control group, $\mathrm{WBA}_{\mathrm{TPP}}-\mathrm{WBA}_{0}$ was significantly different at frequencies between 0.25 and $1.5 \mathrm{kHz}$ with partial eta square varying from 0.02 to 0.09 . In the ETD group,

Table 2. Mean, SEM, and Significance of Difference in $\mathrm{WBA}_{0}$ Between the Control and ETD Groups

\begin{tabular}{lccc}
\hline Frequency $(\mathrm{kHz})$ & $\begin{array}{c}\text { Control Group } n=102 \text { Ears } \\
\text { Mean } \pm \text { SEM }\end{array}$ & $\begin{array}{c}\text { ETD Group } n=43 \text { Ears } \\
\text { Mean } \pm \text { SEM }\end{array}$ & $\begin{array}{c}\text { Significance of Difference Between } \\
\text { Control and ETD Groups }\end{array}$ \\
\hline 0.25 & $0.14 \pm 0.01$ & $0.10 \pm 0.01$ & $0.00^{*}$ \\
0.3 & $0.18 \pm 0.01$ & $0.13 \pm 0.01$ & $0.00^{*}$ \\
0.4 & $0.21 \pm 0.01$ & $0.15 \pm 0.01$ & $0.00^{*}$ \\
0.5 & $0.27 \pm 0.01$ & $0.18 \pm 0.02$ & $0.00^{*}$ \\
0.6 & $0.37 \pm 0.01$ & $0.24 \pm 0.02$ & $0.00^{*}$ \\
0.8 & $0.47 \pm 0.01$ & $0.28 \pm 0.01$ & $0.00^{*}$ \\
1 & $0.59 \pm 0.02$ & $0.31 \pm 0.01$ & $0.00^{*}$ \\
1.25 & $0.66 \pm 0.01$ & $0.29 \pm 0.02$ & $0.00^{*}$ \\
1.5 & $0.67 \pm 0.01$ & $0.31 \pm 0.03$ & $0.00^{*}$ \\
2 & $0.68 \pm 0.01$ & $0.44 \pm 0.03$ & $0.00^{*}$ \\
3.5 & $0.69 \pm 0.02$ & $0.56 \pm 0.04$ & $0.00^{*}$ \\
4 & $0.74 \pm 0.02$ & $0.59 \pm 0.04$ & $0.00^{*}$ \\
5 & $0.77 \pm 0.02$ & $0.58 \pm 0.03$ & $0.00^{*}$ \\
8 & $0.62 \pm 0.02$ & $0.49 \pm 0.03$ & $0.00^{*}$ \\
\hline N & $0.42 \pm 0.02$ & $0.35 \pm 0.03$ & 0.09 \\
\end{tabular}

Notes: SEM $=$ standard error of mean.

*Significant difference with $p<0.05$. 


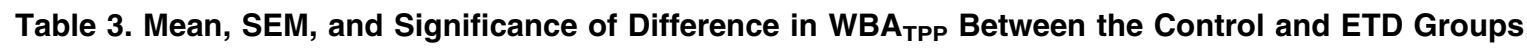

\begin{tabular}{|c|c|c|c|}
\hline Frequency (kHz) & $\begin{array}{c}\text { Control Group } n=102 \text { Ears } \\
\text { Mean } \pm \text { SEM }\end{array}$ & $\begin{array}{c}\text { ETD Group } n=43 \text { Ears } \\
\text { Mean } \pm \text { SEM }\end{array}$ & $\begin{array}{c}\text { Significance of Difference between } \\
\text { Control and ETD Groups }\end{array}$ \\
\hline 0.25 & $0.16 \pm 0.01$ & $0.22 \pm 0.02$ & $0.00^{*}$ \\
\hline 0.3 & $0.20 \pm 0.01$ & $0.28 \pm 0.02$ & $0.00^{*}$ \\
\hline 0.4 & $0.24 \pm 0.01$ & $0.35 \pm 0.02$ & $0.00^{*}$ \\
\hline 0.5 & $0.31 \pm 0.01$ & $0.43 \pm 0.03$ & $0.00^{*}$ \\
\hline 0.6 & $0.43 \pm 0.01$ & $0.53 \pm 0.03$ & $0.00^{*}$ \\
\hline 0.8 & $0.55 \pm 0.01$ & $0.59 \pm 0.03$ & 0.15 \\
\hline 1 & $0.68 \pm 0.01$ & $0.68 \pm 0.02$ & 0.72 \\
\hline 1.25 & $0.73 \pm 0.01$ & $0.71 \pm 0.03$ & 0.49 \\
\hline 1.5 & $0.71 \pm 0.01$ & $0.67 \pm 0.03$ & 0.12 \\
\hline 2 & $0.68 \pm 0.01$ & $0.61 \pm 0.03$ & $0.01^{*}$ \\
\hline 2.5 & $0.68 \pm 0.02$ & $0.63 \pm 0.04$ & 0.18 \\
\hline 3 & $0.73 \pm 0.02$ & $0.66 \pm 0.04$ & 0.06 \\
\hline 4 & $0.76 \pm 0.02$ & $0.61 \pm 0.03$ & $0.00^{*}$ \\
\hline 5 & $0.57 \pm 0.02$ & $0.41 \pm 0.03$ & $0.00^{*}$ \\
\hline 6 & $0.40 \pm 0.02$ & $0.29 \pm 0.03$ & $0.03^{*}$ \\
\hline 8 & $0.22 \pm 0.02$ & $0.23 \pm 0.03$ & 0.73 \\
\hline
\end{tabular}

*Significant difference with $p<0.05$.

$\mathrm{WBA}_{\text {TPP }}-\mathrm{WBA}_{0}$ was significantly different from 0.25 to $2 \mathrm{kHz}$ with effect size ranging from 0.3 to 0.7 .

Furthermore, an ANOVA with repeated measures was performed to compare $\mathrm{WBA}_{\mathrm{TPP}}-\mathrm{WBA}_{0}$ between the control and ETD groups. The results demonstrated that the main effect of ear condition (control versus ETD) was significant $\left.\left[F_{(1,144)}=187.74, p=0.00\right)\right]$. Further analysis using the Bonferroni correction revealed that $\mathrm{WBA}_{\text {TPP-}}-\mathrm{WBA}_{0}$ was significantly between the two groups at all frequencies, except $5 \mathrm{kHz}$.

Figure 2 illustrates the magnitude of difference between $\mathrm{WBA}_{\text {TPP }}$ and $\mathrm{WBA}_{0}$ as a function of MEP. The ETD group was classified into three groups-(a) MEP between -101 and $-200 \mathrm{daPa}$, (b) MEP between -201 and $-300 \mathrm{daPa}$, and (c) MEP between -301 and $-400 \mathrm{daPa}$. Overall, in all three groups, $\mathrm{WBA}_{\mathrm{TPP}}-\mathrm{WBA}_{0}$ increased gradually from $0.25 \mathrm{kHz}$, reached a peak value at $1.25 \mathrm{kHz}$, and reduced greater than $1.25 \mathrm{kHz}$. Between 0.25 and $0.8 \mathrm{kHz}$, $\mathrm{WBA}_{\text {TPP }}-\mathrm{WBA}_{0}$ was reduced with a decreasing MEP. Between 1.25 and $2 \mathrm{kHz}, \mathrm{WBA}_{\mathrm{TPP}}-\mathrm{WBA}_{0}$ for the -201 to $-300 \mathrm{daPa} \mathrm{MEP}$ group was lower than the other two groups. Between 3 and $8 \mathrm{kHz}, \mathrm{WBA}_{\text {TPP }}-\mathrm{WBA}_{0}$ was smaller for the MEP between -101 and -200 daPa group, compared with the other two groups that had MEP $<-200 \mathrm{daPa}$.

Table 4. WBA ${ }_{T P P} W_{B A}$ Significance of Difference and Partial Eta Square for WBA TPP $-W_{B} A_{0}$ in Control and ETD Groups

\begin{tabular}{|c|c|c|c|c|c|c|}
\hline \multirow[b]{2}{*}{$\begin{array}{l}\text { Frequency } \\
(\mathrm{kHz})\end{array}$} & \multicolumn{3}{|c|}{ Control Group } & \multicolumn{3}{|c|}{ ETD Group } \\
\hline & $W_{B A} A_{T P}-W B A_{0}$ & $\begin{array}{l}\text { Significance of } \\
\text { Difference } \\
\text { WBA }_{T P P}-W B A_{O}\end{array}$ & $\begin{array}{c}\text { Partial eta Square for } \\
\text { WBA } \text { TPP }_{\text {WBA }}\end{array}$ & $\mathrm{WBA}_{T P P}-\mathrm{WBA}_{0}$ & $\begin{array}{l}\text { Significance of } \\
\text { Difference } \\
\text { WBA }_{\text {TPP }}-W B A_{0}\end{array}$ & $\begin{array}{c}\text { Partial eta } \\
\text { Square } \\
\text { WBATPP-WBA }_{0}\end{array}$ \\
\hline 0.25 & 0.02 & $0.02^{*}$ & 0.03 & 0.12 & $0.00^{*}$ & 0.33 \\
\hline 0.3 & 0.03 & $0.02^{*}$ & 0.03 & 0.15 & $0.00^{*}$ & 0.24 \\
\hline 0.4 & 0.03 & $0.01^{*}$ & 0.03 & 0.2 & $0.00^{*}$ & 0.36 \\
\hline 0.5 & 0.04 & $0.00^{*}$ & 0.04 & 0.25 & $0.00^{*}$ & 0.39 \\
\hline 0.6 & 0.06 & $0.00^{*}$ & 0.05 & 0.29 & $0.00^{*}$ & 0.45 \\
\hline 0.8 & 0.08 & $0.00^{*}$ & 0.07 & 0.32 & $0.00^{*}$ & 0.57 \\
\hline 1 & 0.09 & $0.00^{*}$ & 0.09 & 0.37 & $0.00^{*}$ & 0.68 \\
\hline 1.25 & 0.07 & $0.00^{*}$ & 0.08 & 0.42 & $0.00^{*}$ & 0.62 \\
\hline 1.5 & 0.04 & $0.03^{*}$ & 0.02 & 0.36 & $0.00^{*}$ & 0.43 \\
\hline 2 & 0.01 & 0.81 & 0 & 0.16 & $0.00^{*}$ & 0.14 \\
\hline 2.5 & -0.01 & 0.56 & 0 & 0.07 & 0.17 & 0.02 \\
\hline 3 & -0.01 & 0.59 & 0 & 0.07 & 0.2 & 0.02 \\
\hline 4 & -0.01 & 0.54 & 0 & 0.03 & 0.44 & 0.01 \\
\hline 5 & -0.05 & 0.07 & 0.02 & -0.07 & 0 & 0.03 \\
\hline 6 & -0.02 & 0.58 & 0 & -0.06 & 0.18 & 0.02 \\
\hline 8 & -0.01 & 0.85 & 0 & -0.07 & 0.19 & 0.02 \\
\hline
\end{tabular}

*Significant difference with $p<0.05$. 


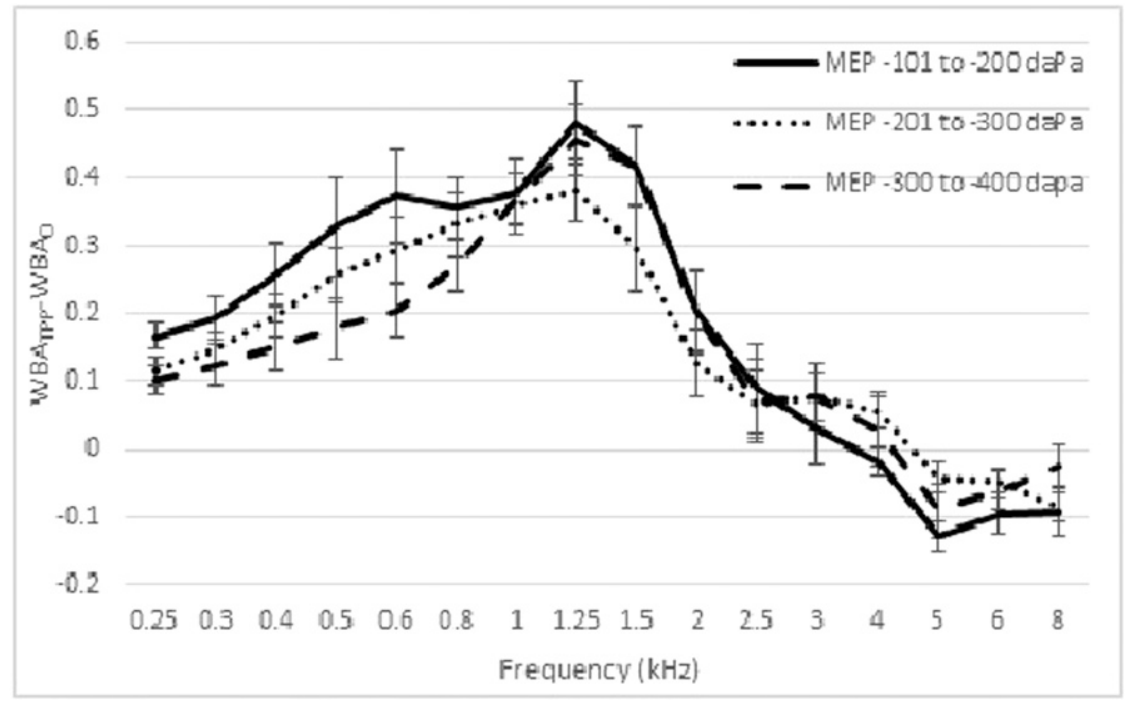

Figure 2. Difference between $\mathrm{WBA}_{\text {TPP }}$ and $\mathrm{WBA}_{0}$ as a function of MEP.

The results of the present study were compared with mean WBA at $0 \mathrm{daPa}$ and TPP in a separate group of six ears with surgically confirmed OME and with NMEP (not included in the Participants section). The participants were 2.8-6.2 years of age and their MEP ranged from -110 to $-335 \mathrm{daPa}$. Audiometry, tympanometry, and WBA measurements were performed a few hours before the surgery, and confirmation of fluid was provided by the ENT surgeon following surgery. As illustrated in Figure 3, $\mathrm{WBA}_{0}$ of the OME group was lower than that of the control group at all frequencies. $\mathrm{WBA}_{0}$ of the OME group was lower than the $\mathrm{WBA}_{0}$ of ETD group from 0.25 to $1 \mathrm{kHz}$ and higher from 1.25 to $1.5 \mathrm{kHz}$. $\mathrm{WBA}_{0}$ of both ETD and OME groups was similar greater than $1.5 \mathrm{kHz}$. By contrast, $\mathrm{WBA}_{\mathrm{TPP}}$ of the OME group was lower than that of the control group at all frequencies except 0.4 and $0.5 \mathrm{~Hz}$. WBA $\mathrm{WPP}_{\mathrm{TP}}$ of $\mathrm{OME}$ group was lower than that of the ETD group at all frequencies. However, the difference was larger between 0.8 and $2 \mathrm{kHz}$.

The magnitude of difference between $\mathrm{WBA}_{\text {TPP }}$ and $\mathrm{WBA}_{0}$ for the three groups is shown in Figure 4. As illustrated in this figure, the control group showed the least difference between $\mathrm{WBA}_{\mathrm{TPP}}$ and $\mathrm{WBA}_{0}$ across entire frequency region between 0.25 and $8 \mathrm{kHz}$. WBA in the control group was only 0.06 to 0.09 higher than $\mathrm{WBA}_{0}$ between 0.6 and $1.25 \mathrm{kHz}$ and between 0.01 and 0.04 at other frequencies. In the ETD group, the $\mathrm{WBA}_{\text {TPP }}$ was 0.12 to 0.42 higher than the $\mathrm{WBA}_{0}$ between 0.25 and $2 \mathrm{kHz}$, with the highest value of 0.42 at $1.25 \mathrm{kHz}$. The difference between the two conditions was more evident between 0.6 and $2 \mathrm{kHz}$ with $>0.2$

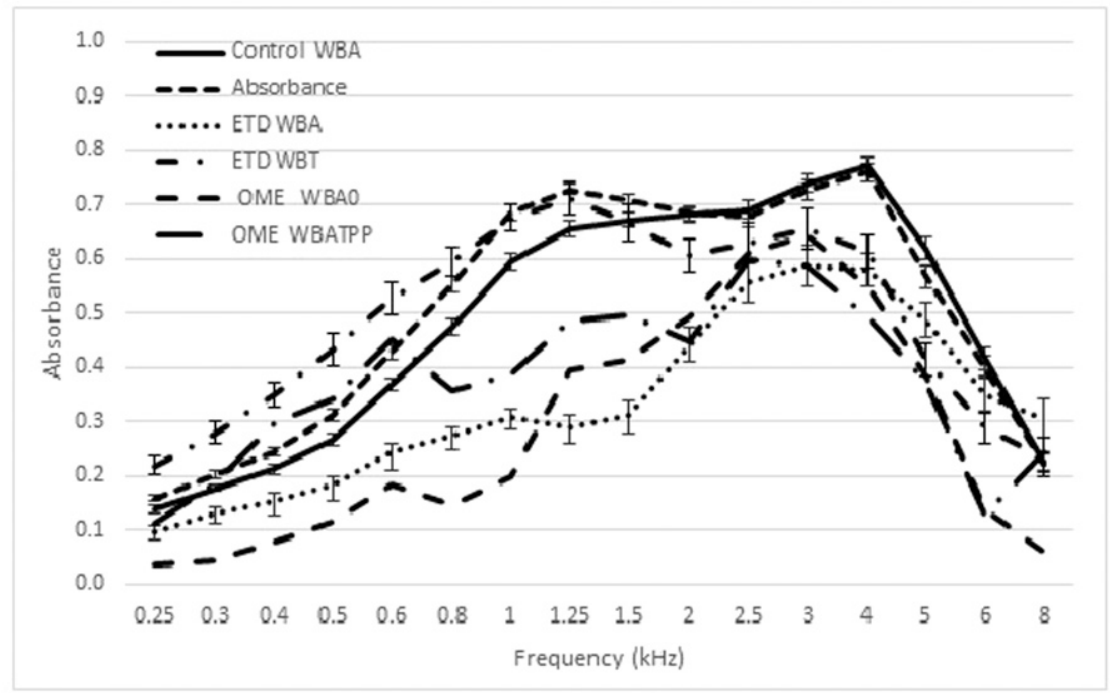

Figure 3. $\mathrm{WBA}_{0}$ and $\mathrm{WBA}_{\mathrm{TPP}}$ in the control, ETD, and OME groups. 


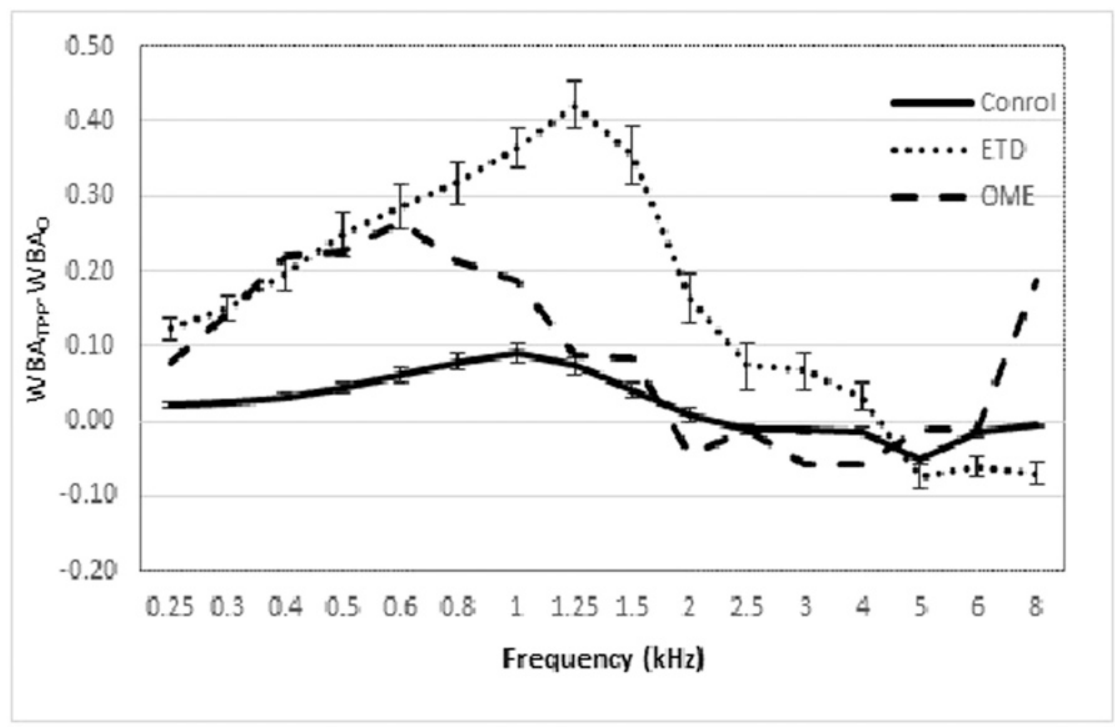

Figure 4. Difference between $\mathrm{WBA}_{\mathrm{TPP}}$ and $\mathrm{WBA}_{0}$ for the control, ETD, and OME groups.

improvement in absorbance at TPP relative to $0 \mathrm{daPa}$. The $\mathrm{WBA}_{\text {TPP }}$ of the OME group was $0.08-0.27$ higher than $\mathrm{WBA}_{0}$ between 0.25 and $1.5 \mathrm{kHz}$, with the highest value of 0.27 at $0.6 \mathrm{kHz}$.

\section{DISCUSSION}

$\mathrm{T}$ his study compared WBA at $0 \mathrm{daPa}$ and TPP in healthy ears and ears with ETD without effusion. $\mathrm{WBA}_{0}$ was significantly lower for the ETD group than for the control group across all frequencies except 6 and $8 \mathrm{kHz}$ (see Figure 2). The largest difference in $\mathrm{WBA}_{0}$ between the two groups occurred in the frequency range from 1 to $1.5 \mathrm{kHz}$, which is a characteristic attribute of ears with ETD. As expected, WBA TPP $_{\text {for the ETD group }}$ restored to normal levels comparable to that for the control group.

Results of the present study concur with the results of previous studies that have demonstrated reduced WBA at ambient pressure in ears with ETD or NMEP, especially between 0.8 and $1.5 \mathrm{kHz}$. There are not many studies that have studied WBA in ears with confirmed ETD. Ibraheem (2014) studied WBA at ambient pressure in three patients with ETD and NMEP ranging from -155 to $-318 \mathrm{daPa}$. The overall pattern of WBA in ETD patients showed reduced WBA at low to mid frequencies up to $2.2 \mathrm{kHz}$ and the reduced WBA effect spread to higher frequencies with the severity of ETD. However, a significant difference in WBA between the normal and ETD patients was found only at 0.25 $\mathrm{kHz}$. Ibraheem (2014) attributed the possibility of a missed underlying pathology besides ETD as a possible cause for this finding.

Several studies have reported similar findings in ears with NMEP, which is a consequence of ETD. NMEP increases the stiffness of the middle ear system, resulting in alterations to the sound conduction characteristics (Gyo and Goode, 1987; Murakami et al, 1997). Hunter et al (2008) compared WBA at ambient pressure in 124 ears with normal MEP with nine ears with mild NMEP (TPP $<-100 \mathrm{daPa}$ ) and reported that average WBA was lower in the NMEP group for all frequencies up to $\sim 4$ $\mathrm{kHz}$. Beers et al (2010) analyzed WBA at ambient pressure in school-aged children with normal middle ear status and NMEP and reported that with a mild degree of NMEP ( -100 to $-199 \mathrm{daPa}$ ), a 0.2 mean reduction in absorbance was present between 0.4 and $1.8 \mathrm{kHz}$. Similarly, Sanford and Brockett (2014) also reported decreased absorbance between 0.5 and $2 \mathrm{kHz}$ in eight children with NMEP.

Shaver (2010) studied WBA at ambient pressure and self-induced NMEP varying from -40 to $-125 \mathrm{daPa}$ in eight healthy adults. Shaver reported significantly reduced WBA from 0.5 to $1.5 \mathrm{kHz}$ with NMEP compared with baseline ambient WBA, with maximum reduction occurring at $1 \mathrm{kHz}$ for pressures down to $-95 \mathrm{daPa}$ and at $1.4 \mathrm{kHz}$ for pressures down to $-125 \mathrm{daPa}$. There was a corresponding smaller increase in WBA in the high frequencies between 4 and $6 \mathrm{kHz}$.

Margolis et al (1999) and Sanford and Feeney (2008) described absorbance measures in adults at various ear canal pressures. Positive ear canal pressure can be compared with NMEP because of the similarity in tympanic membrane position. According to Sanford and Feeney (2008), the application of positive ear canal pressure resulted in 0.17 to 0.2 decrease in $\mathrm{WBA} \sim 1 \mathrm{kHz}$, whereas WBA increased with frequency greater than $2.2 \mathrm{kHz}$ with the largest increase of $0.11 \sim 2.85 \mathrm{kHz}$.

In the present study, $\mathrm{WBA}_{\mathrm{TPP}}$ was higher than $\mathrm{WBA}_{0}$ in both groups. In the control group, $\mathrm{WBA}_{\text {TPP }}$ was 0.06 
to 0.09 higher than $\mathrm{WBA}_{0}$ between 0.6 and $1.5 \mathrm{kHz}$ and only 0.01 to 0.04 higher than $\mathrm{WBA}_{0}$ at other frequencies. On the other hand, $\mathrm{WBA}_{\text {TPP }}$ in the ETD group demonstrated 0.12 to 0.42 increase between 0.25 and $2 \mathrm{kHz}$ compared with $\mathrm{WBA}_{0}$. WBA $\mathrm{WPP}_{\text {TP }}$ was 0.29 and 0.42 higher between 0.6 and $1.5 \mathrm{kHz}$. Presently, there are no clinical studies on pressurized WBA in ears with ETD for comparison with the present study. However, comparable results are available from studies investigating WBA under compensatory (positive ear canal pressure equal to the negative shift in MEP self-induced by a participant) conditions. Shaver (2010) reported 0.2-0.4 improvement in WBA between 1 and $1.5 \mathrm{kHz}$. Significant decrease in WBA was also found between 6 and $8 \mathrm{kHz}$.

As shown in Figure 2, maximal improvement of $\mathrm{WBA}_{\text {TPP }}$ was observed in the ETD group in the frequency region from 0.8 to $1.5 \mathrm{kHz}$. This concurs with the findings of other studies that have reported the mid frequency region between 0.8 and $2 \mathrm{kHz}$ being optimal for detecting NMEP (Beers et al, 2010; Voss et al, 2012; Shaver and Sun, 2013; Robinson et al, 2016). If the ear canal pressure differs from the MEP, a reduction in low frequency transmission occurs (MØller, 2000). Human cadaver temporal bone studies have shown that the formation of pressure gradients across the tympanic membrane results in alteration of the middle ear mechanics. Even a small NMEP of $-50 \mathrm{daPa}$ reduced peak-to-peak umbo displacement less than $\sim 1$ to $1.2 \mathrm{kHz}$. As the pressure difference across the tympanic membrane increased, the highest frequency at which umbo displacement occurred shifted upward between 1.4 and $3 \mathrm{kHz}$ (Gyo and Goode, 1987; Murakami et al, 1997; Shaver, 2010).

Measurement of WBA at TPP compensates for the pressure differential across the tympanic membrane and, hence, improves the energy transmission, especially in the low-to-mid frequencies. Acoustic reflex and otoacoustic emission studies have shown improvement in response detection when the MEP was compensated. For instance, applying ear canal pressure to counteract nonzero MEP during acoustic reflex measurement allows for detection at lower intensity levels compared with measurements at ambient pressure (Rizzo and Greenberg, 1979; Ruth et al, 1982). Sun and Shaver (2009) measured distortion product otoacoustic emissions at ambient pressure and self-induced NMEP conditions. They reported a reduction in otoacoustic emissions with NMEP with the largest reduction occurring at $1 \mathrm{kHz}$ and below, with minimal changes at $2 \mathrm{kHz}$. Hof et al (2005) measured TEOAEs under ambient pressure (uncompensated) and at MEP (compensated) and found that with compensated MEP, the TEOAE response increased by about $2 \mathrm{~dB}$. They reported the largest increase $\sim 1$ and $2 \mathrm{kHz}$ with no significant changes in TEOAE responses at 3 and $4 \mathrm{kHz}$.
Hof et al concluded that equalizing the MEP via alteration of pressure in the external ear canal increased TEOAE amplitude. They suggested that this would be beneficial for children with NMEP, as it would allow the clinicians to quickly evaluate compensated OAEs, and help rule out a sensorineural hearing loss.

\section{Implications of the Study}

It is important for clinicians to understand how WBA is affected in middle ear pathologies, including ETD. Understanding the effects of NMEP on WBA will assist in better differential diagnosis of similar pathologies. Although TPP is commonly used as an indicator of MEP, it does not describe the effects of altered MEP on sound transmission through the middle ear system. Instead, comparison of WBA at TPP and 0 daPa may provide additional and potentially diagnostically useful information about the conductive conditions of individual ears. Margolis et al (1999) presented a case in which middle ear pathology coexisted with NMEP. Although the absorbance at ambient pressure was similar to the pressurized absorbance pattern of a normal ear, an abnormal pattern was obtained, indicating pathologic middle ear changes in addition to NMEP. Hence, Margolis et al suggested that it may be necessary to compensate for MEP (by varying the ear canal pressure) to detect middle ear pathology.

In the present study, a differential pattern of WBA at TPP relative to 0 daPa was observed between ears with ETD and ears with OME and NMEP. WBA ${ }_{0}$ was reduced in both ETD and OME conditions. However, in ears with ETD, $\mathrm{WBA}_{\text {TPP }}$ restored to near normal values between 0.6 and $1.5 \mathrm{kHz}$, whereas in ears with OME and NMEP, $\mathrm{WBA}_{\mathrm{TPP}}$ remained significantly low in the low to mid frequencies.

Thus, assessment of WBA at $0 \mathrm{daPa}$ and TPP has the potential to identify ETD with or without effusion. This is important especially in young children or some adults who are unable to perform maneuvers such as Toynbee or Valsalva during ETD assessment. Nonetheless, further research is needed to verify the results using test performance measures to determine whether WBA at TPP and 0 daPa can objectively determine the presence of ETD or OME with NMEP.

\section{Limitations of the Study}

The large age range of patients in the present study could have confounded the results in the present study. The control group had participants in the age range of 3-23 years, whereas the ETD group had participants in the age range of 3-48 years. It has been shown that the elastic properties of the middle ear vary with age and are reflected in the acoustic characteristics. It is possible that the WBA in the ETD group could have been 
influenced by age as young normal-hearing children may have a preexisting slight NMEP. Therefore, it is highly preferable to include participants with comparable age for both the control and experimental groups.

\section{Conclusions}

Although the $\mathrm{WBA}_{0}$ in the ETD group was lower than that of the control group, the WBA $\mathrm{WPP}_{\mathrm{TP}}$ improved significantly and approached normative values, especially between 0.8 and $1.5 \mathrm{kHz}$. A similar improvement in absorbance at TPP was not noted in ears with OME and NMEP. Hence, a comparison of $\mathrm{WBA}_{0}$ and $\mathrm{WBA}_{\text {TPP }}$ can provide potentially useful diagnostic information, and hence can be used as an adjunct tool to evaluate ETD. However, age appropriate normative values for WBA need to be developed to determine objective indicators of ETD in clinical population.

Acknowledgments. The authors would like to acknowledge the support of Institute of Surgery at the Townsville Hospital. The authors also acknowledge the support of Joshua Myers, Alehandrea Manuel, and Annie Chan in assisting with data collection and Ms. Karen Nielsen in administrative tasks including data entry.

\section{REFERENCES}

Aithal S, Kei J, Driscoll C. (2014) Wideband reflectance in young infants (0-6 months): a cross-sectional study. J Am Acad Audiol $25: 471-478$.

Allen JB, Jeng PS, Levitt H. (2005) Evaluation of human middle ear function via an acoustic power assessment. J Rehabil Res Dev 42:63-78.

Beers AN, Shahnaz N, Westerberg BD, Kozak FK. (2010) Wideband reflectance in normal Caucasian and Chinese school-age children and in children with otitis media with effusion. Ear Hear 31: 221-223.

Bluestone C. (2005) Eustachian Tube: Structure, Function, Role in Otitis Media. London: Hamilton, BC Decker, Inc.

Bluestone C, Klein JO. (2007) Otitis Media in Infants and Children. 4th ed. London: Hamilton, BC Decker, Inc.

Ellison JC, Gorga MA, Cohn E, Fitzpatrick DF, Sanford CA, Keefe DH. (2012) Wideband acoustic transfer functions predict middle-ear effusion. Laryngoscope 122:887-894.

Elner A, Ingelstedt S, Ivarasson A. (1971) The elastic properties of the tympanic membrane. Acta Otolaryngol 72:397-403.

Greenhouse SW, Geisser S. (1959) On the methods in the analysis of provide data. Psychometrika 9:95-112.

Gyo K, Goode RL. (1987) Effects of middle ear pressure changes on umbo vibraion. Auris Nasus Larynx 14:131-137.

Hof JR, Anteunis LJC, Cheault MN, van Dijk P. (2005) Otoacoustic emissions at compensated middle ear pressure in children. Intl J Audiol 44:317-320.
Hunter LL, Feeney MP, Miller JAL, Jeng PS, Bohning S. (2010) Wideband reflectance in newborns: normative regions and relationship to hearing-screening results. Ear Hear 31:599-610.

Hunter LL, Shahnaz N. (2014) Acoustic Immittance Measures: Basics and Advanced Practice. San Diego, CA: Plural Publishing.

Hunter LL, Tubaugh L, Jackson A, Propes S. (2008) Wideband middle ear power measurement in infants and children. $J \mathrm{Am}$ Acad Audiol 19:309-324.

Ibraheem WM. (2014) Clinical diagnosis of middle ear disorders using wideband energy reflectance in adults. Adv Arab Acad Audio-Vestibul J 1:87-96.

Interacoustics. (2015) Titan: Technical Specifications. http://www. iinteracoustics.us/titan/support. Accessed August 22, 2017.

Jerger J. (1970) Clinical experience with impedance audiometry. Arch Otolaryngol 92:311-324.

Keefe DH, Sanford CA, Ellison JC, Fitzpatrick DF, Gorga MA. (2012) Wideband aural acoustic absorbance predicts conductive hearing loss in children. Int J Audiol 51:880-891.

Keefe DH, Simmons JL. (2003) Energy transmittance predicts conductive hearing loss in older children and adults. $J$ Acoust Soc Am 114:3217-3238.

Lildholdt T. (1980) Negative middle ear pressure. Variations by season and sex. Ann Otol Rhinol Laryngol 89(68, Suppl):67-70.

Margolis RH, Saly GL, Keefe DH. (1999) Wideband reflectance tympanometry in normal adults. J Acoust Soc Am 106:265-280.

MØller AR. (2000) Hearing: its Physiology and Pathophysiology. San Diego, CA: Academic Press.

Murakami S, Gyo K, Goode RL. (1997) Effect of middle ear pressure change on middle ear mechanics. Acta Otolaryngol 117:390-395.

Nakajima HH, Rosowski JJ, Shahnaz N, Voss SE. (2012) Assessment of ear disorders using power reflectance. Ear Hear 34:48S-53S.

Podoshin L, Fradis M, Mallatskey S, Ben-David J. (1996) Tympanoplasty in adults: a five-year survey. Ear Nose Throat $J$ 75: $149-152$.

Prieve BA, Vander Werff KR, Preston JL, Georgantas L. (2013) Identification of conductive hearing loss in young infants using tympanometry and wideband reflectance. Ear Hear 34: $168-178$

Renall U, Holmquist J. (1976) Tympanometry revealing middle ear pathology. Ann Otol Rhinol Laryngol 85(25, Suppl):209-215.

Rizzo SJ, Greenberg HJ. (1979) Influence of ear canal air pressure on acoustic reflex threshold. J Am Aud Soc 5:21-24.

Robinson SR, Thompson S, Allen JB. (2016) Effects of negative middle ear pressure on wideband acoustic immittance in normal hearing adults. Ear Hear 37:452-464.

Ruth RA, Tucci DL, Nilo ER. (1982) Effects of ear canal pressure on threshold and growth of the acoustic reflex. Ear Hear 3:39-41.

Sanford CA, Brockett JE. (2014) Characteristics of wideband acoustic immittance in patients with middle ear dysfunction. $J$ Am Acad Audiol 25:425-440.

Sanford CA, Feeney MP. (2008) Effects of maturation on tympanometric wideband acoustic transfer functions in human infants. $J$ Acoust Soc Am 104:2106-2122. 
Sanford CA, Hunter LL, Feeney MP, Nakajima HH. (2013) Wideband acoustic immittance: tympanometric measures. Ear Hear 34: $65 \mathrm{~s}-71 \mathrm{~s}$.

Sanford CA, Keefe DH, Liu Y-W, Fitzpatrick DF, McCreery RW, Lewis DE, Gorga MP. (2009) Sound-conduction effects on distortionproduct otoacoustic emission screening outcomes in newborn infants: test performance of wideband acoustic transfer functions and 1-kHz tympanometry. Ear Hear 30:635-652.

Schröder S, Lehmann M, Sauzet O, Ebmeyer J, Sudhoff H. (2015) A novel diagnostic tool for chronic obstructive Eustachian tube dysfunction-the Eustachian tube score. Laryngoscope 125: 703-708.

Shahnaz N. (2008) Wideband reflectance in neonateal intensive care units. J Am Acad Audiol 19:419-429.

Shahnaz N, Bork K. (2006) Wideband reflectance norms for Caucasian and Chinese young adults. Ear Hear 27:774-788.

Shahnaz N, Bork K, Polka L, Longridge N, Bell D, Westerberg BD. (2009) Energy reflectance and tympanometry in normal and otosclerotic ears. Ear Hear 30:219-233.
Shaver MD. (2010) Wideband Energy Reflectance Measurements: Normative Study and Effects of Negative and Compensated Middle Ear Pressures, Ph.D. thesis, Wichita State University. http:// hdl.handle.net/10057/3657. Accessed August 30, 2017.

Shaver MD, Sun XM. (2013) Wideband energy reflectance measurements: effects of negative middle ear pressure and application of a pressure compensation procedurue. Acousut Soc A 13:332341 .

Sun XM, Shaver MD. (2009) Effects of negative middle ear pressure on distortion product otoacoustic emissions and application of a compensation procedure in humans. Ear Hear 30:191-202.

Tysome JR. (2015) Eustachian tube dysfunction consensus. Editorial. Clin Otolaryngol 40:406.

Vander Werff KR, Prieve BA, Georgantas LM. (2007) Test-retest reliability of wideband reflectance measures in infants under screening and diagnostic test conditions. Ear Hear 28:669-681.

Voss SE, Merchant GR, Horton NJ. (2012) Effects of middle ear disorders on power reflectance measured in cadaveric ear canals. Ear Hear 33:195-208. 